\title{
CALCULATION OF OUTER CRACK STRESS INTENSITY FACTORS FOR NOZZLE JUNCTIONS IN CYLINDRICAL PRESSURE VESSELS USING FCPAS
}

\author{
Murat Bozkurt \\ Department of Mechanical \\ and Aerospace Engineering \\ University of Strathclyde \\ 75 Montrose Street, G1 1XJ \\ Glasgow, UK \\ E-mail: murat.bozkurt@strath.ac.uk
}

\author{
David Nash \\ Department of Mechanical \\ and Aerospace Engineering \\ University of Strathclyde \\ 75 Montrose Street, G1 1XJ \\ Glasgow, UK \\ E-mail: d.nash@strath.ac.uk
}

\author{
Asraf Uzzaman \\ School of Computing, \\ Engineering and Physical Science, \\ University of the West of Scotland, \\ Paisley, UK \\ E-mail: asraf.uzzaman@uws.ac.uk
}

\section{ABSTRACT}

Pressure vessels can be subjected to various external local forces and moments acting in combination with main internal pressure. As a result of the stress system set up, and in the presence of attachment welds, surface cracks can occur on the interior and exterior walls. If these cracks cannot be detected at an early stage, there is a real potential for the vessel to rupture with obvious dangerous consequences. The behavior of fractured or geometric discontinuity structures can be investigated with linear elastic fracture mechanics (LEFM) parameters. The stress intensity factor (SIF) is the leading one, and with correct calculations, it can produce the stress intensity in the crack tip region. In cylinder-cylinder intersections subject to local loads, the maximum stress distribution occurs in and around these opening areas and failure in the system usually occurs in this region.

Using this approach, the present study develops threedimensional mixed mode stress intensity factor solutions on for external cracks on nozzle joints in cylindrical pressure vessels nozzle junctions for a variety of geometrical configurations. This was undertaken using a finite element approach and employing a bespoke software tool and solver, FCPAS - Fracture and Crack Propagation Analysis System - to create the finite element mesh and propagation characteristics. From this, a parameter study examining the influence of the crack shape, size and position was carried out with a fixed pressure vessel nozzle cylinder intersection geometry configuration and the appropriate stress intensity factors identified and reported. The FCPAS tool is shown to be an effective approach to modelling and characterizing cracks in pressure vessel nozzles.

Keywords: Pressure vessel, nozzle intersection, local loads, stress intensity factor, fracture, crack, finite element analysis

$\begin{array}{cl}\text { NOMENCLATURE } \\ \text { a } & \text { crack depth } \\ \mathrm{c} & \text { crack radius } \\ \mathrm{d}_{\mathrm{i}} & \text { inside diameter of nozzle } \\ \mathrm{d}_{\mathrm{o}} & \text { outside diameter of nozzle } \\ \mathrm{D}_{\mathrm{i}} & \text { inside diameter of shell } \\ \mathrm{D}_{\mathrm{o}} & \text { outside diameter of shell } \\ \mathrm{KI} & \text { SIF due to mode-I loading } \\ \mathrm{KII} & \text { SIF due to mode-II loading } \\ \mathrm{KIII} & \text { SIF due to mode-III loading } \\ \mathrm{M}_{\mathrm{C}} & \text { circumferential moment } \\ \mathrm{M}_{\mathrm{L}} & \text { longitudinal moment } \\ \mathrm{P}_{\text {int }} & \text { internal pressure } \\ \mathrm{SIF} & \text { Stress Intensity Factor } \\ \mathrm{t} & \text { thickness of the nozzle } \\ \mathrm{T} & \text { thickness of the shell } \\ \mathrm{V}_{\mathrm{C}} & \text { circumferential force } \\ \mathrm{V}_{\mathrm{L}} & \text { longitudinal force }\end{array}$




\section{INTRODUCTION}

Potential failures caused by breakage problems are an important issue in structural integrity evaluations of pressure vessels. Load carrying capacity is limited in such thin-walled structures. In such structures, buckling and compression conditions caused by various loadings such as internal pressure and external loads may cause a decrease in the limit loads in the containers and can lead to bursting. Such problems usually start with small surface cracks and these cracks could be grown in a path until eventually the structure deteriorates. Cracks that may occur in pressurized vessels may be caused by manufacturing procedures or in various environmental effects. One of the most important problems that arises in the industry is the evaluation and consideration of the safety criteria of structures such as pressure vessels throughout their service life. For this reason, various studies have been conducted to examine the behavior of pressure vessels and pipes containing cracks.

In pressure vessels, nozzles are one of the parts with the highest and most complex stress systems due to the presence of the opening zone. For this reason, crotch corners are one of the most likely areas where crack initiation and fracture events may occur. Firstly, Liu et al. [1] performed linear elastic fracture analysis for a Reactor Pressure Vessel (RPV). It was assumed here that cracks may occur at the nozzle-cylinder intersections where the stress is most concentrated. As a result, calculations were developed for different crack shapes and design conditions that did not endanger safety. In another study, possible elliptical cracks in the nozzle-vessel junction area were discussed by Murtaza et al. [2]. Here, the effect of pressure plus thermal stress on SIF values were investigated. It was emphasized that the applications made were completely safe in terms of fracture mechanics. On the other hand, Jin et al. [3], obtained fracture driving forces $(\mathrm{KI}, \mathrm{J})$ and $\mathrm{T}$ stresses in RPV corner cracks by using traditional calculation methods. Additionally, they put forward a simplified calculation process that can estimate the Weibull stress calculation occurring under this stress field and along the crack tip more effectively with the modified boundary layer model. Another study on cracks in the Reactor Pressure Vessel was done by Susmikanti [4]. In this study, J-Integral and SIF calculations were chosen as crack parameters. Also, it was stated that the 3D modeling was in accordance with the SIF calculations and some critical loading conditions that could cause breakage specified.

Akrami et al. [5] studied the effect of buckling load on cracks in cylindrical shells. In this study, which was based on analytical and numerical evaluations, parameters such as cylinder length, crack location and intensity constitute the basic criteria. At the end of the study, the authors proposed an empirical equation to compare buckling loads in cracked and uncracked structures. Moreover, the buckling behavior of broken cylinders was also discussed by Estekanchi and Vafai [6]. In Estekanchi's study, a program has been developed for FE modeling of cracks in different lengths and directions. Then, buckling behavior in tensile and compression loads in these models was investigated.
Besides these, Alizadeh [7] validated his model using the extended finite element method for various parameters and investigated the use of CFRP laminates to strengthen the container in crack problems.

In this study, inclined cracks occurring on the inner surface of cylindrical pressure vessels were investigated by Subbaiah [8]. It was given point to here that the critical slope was 30 degrees and as this angle increased, the Mode-II loading became more dominant. Furthermore, SIF calculations were made simultaneously for the presence of more than one crack with the numerical simulation.

In addition to all these studies, there are many additional studies in the literature related to SIF calculations and the development of these calculations. These equations are also still open to new approaches and interpretation. In 1982, Newman and Raju [9] studied internal surface cracks in cylindrical pressure vessels. In the study, stress intensity factors were determined by changing parameters such as crack length, crack depth, wall thickness at certain rates. The study includes calculations in mode-I opening mode only. Empirical equations in the study were developed with extended parameter variations. The results obtained have been confirmed by other results in the literature.

In 1991, Kirkhope [10] derived empirical equations for the $\mathrm{KI}$ calculation at the deepest crack location for specific crack depth / crack length ratios using the KI values of single and multiple cracks occurring in thin-walled cylinders in his study. Also, Hachi et al. [11] developed a computer code for SIF calculations of elliptical cracks in the Mode I opening state. The results obtained were compared with other methods in the literature and it was stated to have high accuracy. In 2002, Ayhan and Nied [12] conducted a study on the detailed general formulation of enriched crack tip elements for three-dimensional crack problems. The advantage of this formulation over other approaches is that the same calculation algorithm can be used for more complex crack tip areas. In another study by Ayhan [13], a three-dimensional methodology was presented for simulation of fatigue crack propagation. With this method, named Fracture and Crack Propagation Analysis System (FCPAS), mixed mode surface cracks can be easily calculated. Bozkurt et al. [14] conducted numerical and experimental studies on the mode I-III fracture sample using the finite element method and FCPAS [13]. Kurt [15] on the other hand, obtained SIF solutions for mixedmode cracks on the interior surfaces of spherical pressure vessels, again using FEM and FCPAS [13].

In this study, calculations will be presented for elliptical cracks that are likely to occur on upper welding area on nozzle outer wall surface crack, which are one of the most important components in cylindrical vessels. These calculations are performed using the Fracture and Crack Propagation Analysis System (FCPAS). The stress intensity factor (SIF) is the leading one and, with correct calculations, it can produce the stress intensity in the crack tip region. Using this approach, the current work develops alternative three-dimensional mixed-mode stress intensity factor (3-D SIF) solutions for external cracks in nozzle 
joints in cylindrical pressure vessels for various geometric configurations.

\section{PROBLEM DESCRIPTION and MIXED MODE STRESS INTENSITY FACTORS (SIFS) \\ CALCULATIONS METHOD}

Crack problems, which are frequently encountered in engineering structures and industry, are very interesting issues in terms of their safe detection and finding the necessary solutions. Recent studies have mainly focused on the investigation of crack propagation behavior of materials under simple mode-I loading. However, engineering materials can also be exposed to loads called mixed mode, which include mode-II and mode-III loading types in terms of operating conditions. In cylindrical pressure vessels with nozzle connections, critical stress points may vary due to local loads and internal pressure affecting the system. Bozkurt et al. investigated in detail the determination of these critical locations under internal pressure and external loading in the elastic region, the stress behavior and limit loading conditions of the system under any load [16,17]. It has been seen in these studies that while maximum stress concentrates around the crotch corner (nozzle junction zones) in vessels under only internal pressure, these stress regions may change with some external loads such as $\mathrm{V}_{\mathrm{C}}, \mathrm{V}_{\mathrm{L}}, \mathrm{M}_{\mathrm{C}}, \mathrm{M}_{\mathrm{L}}$ affecting the system.

In this paper, mixed mode stress intensity factors will be calculated for some potential crack profiles that may occur on the nozzle exterior wall. In 3D mixed mode crack propagation problems, the size and direction of the crack varies with the magnitude and direction of the forces acting on the system.

FCPAS (Fracture and Crack Propagation Analysis System) is used for mixed-mode 3D SIF calculations in. This program provides efficient and accurate calculation of stress intensity factors (KI, KII and KIII) by using enriched elements along the crack tip. Figure 1 shows the nozzle separated from the cylinder and a representative surface crack placed over the welding zone. In the finite element model with cracks, the elements touching the crack tip are defined as enriched elements and a representative image of the enriched elements is given in Figure 2.

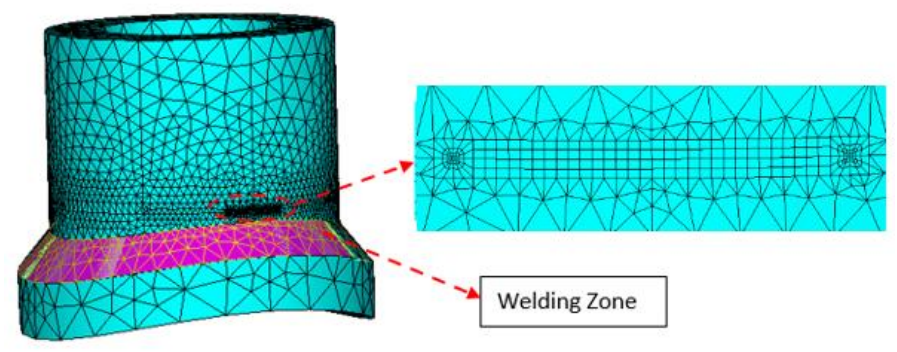

FIGURE 1: OVERALL VIEW OF THE MESHED NOZZLE MODEL AND BLOWN-UP IMAGE OF THE CRACK REGION

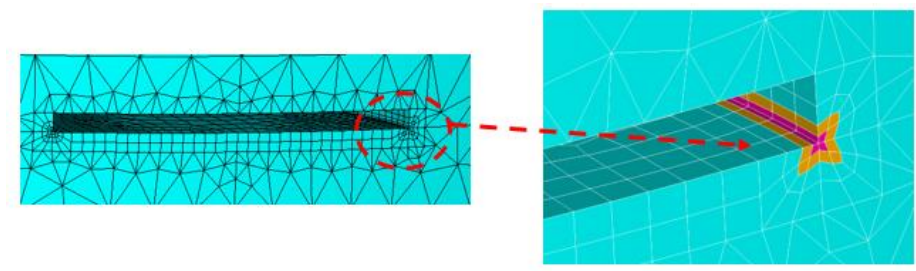

FIGURE 2: A REPRESENTATIVE VIEW OF ENRICHED AND TRANSITION ELEMENTS RUNNING ALONG THE CRACK

The elements shown in Figure 2 that directly touch the crack front are enriched elements and colored in pink. The elements represented in orange color are called transition elements and they act as a bridge with other regular finite elements moving along the crack path.

In addition to the conventional finite element formulation, these elements also contain the stress intensity factors located at the crack tip as unknown. For an integration point in $\xi, \eta$ and $\rho$ local coordinates in an enriched element, the $u, v$ and $w$ displacements are calculated with the equations $[12,18]$ given below.

$$
\begin{aligned}
u(\xi, \eta, \rho)= & \sum_{j=i}^{m} N_{j}(\xi, \eta, \rho) u_{j}+Z_{0}(\xi, \eta, \rho)\left(f_{u}(\xi, \eta, \rho)-\right. \\
& \left.\sum_{j=i}^{m} N_{j}(\xi, \eta, \rho) f_{u j}\right)\left(\sum_{i=1}^{n t i p} N_{i}(\Gamma) K_{I}^{i}\right)+ \\
& Z_{0}(\xi, \eta, \rho)\left(g_{u}(\xi, \eta, \rho)-\right. \\
& \left.\sum_{j=i}^{m} N_{j}(\xi, \eta, \rho) g_{u j}\right)\left(\sum_{i=1}^{n t i p} N_{i}(\Gamma) K_{I I}^{i}\right)+ \\
& Z_{0}(\xi, \eta, \rho)\left(h_{u}(\xi, \eta, \rho)-\right. \\
& \left.\sum_{j=i}^{m} N_{j}(\xi, \eta, \rho) h_{u j}\right)\left(\sum_{i=1}^{n t i p} N_{i}(\Gamma) K_{I I}^{i}\right) \\
v(\xi, \eta, \rho)= & \sum_{j=i}^{m} N_{j}(\xi, \eta, \rho) v_{j}+Z_{0}(\xi, \eta, \rho)\left(f_{v}(\xi, \eta, \rho)-\right. \\
& \left.\sum_{j=i}^{m} N_{j}(\xi, \eta, \rho) f_{v j}\right)\left(\sum_{i=1}^{n t i p} N_{i}(\Gamma) K_{I}^{i}\right)+ \\
& Z_{0}(\xi, \eta, \rho)\left(g_{v}(\xi, \eta, \rho)-\right. \\
& \left.\sum_{j=i}^{m} N_{j}(\xi, \eta, \rho) g_{v j}\right)\left(\sum_{i=1}^{n t i p} N_{i}(\Gamma) K_{I I}^{i}\right)+ \\
& Z_{0}(\xi, \eta, \rho)\left(h_{v}(\xi, \eta, \rho)-\right. \\
& \left.\sum_{j=i}^{m} N_{j}(\xi, \eta, \rho) h_{v j}\right)\left(\sum_{i=1}^{n t i p} N_{i}(\Gamma) K_{I I I}^{i}\right) \\
w(\xi, \eta, \rho)= & \sum_{j=i}^{m} N_{j}(\xi, \eta, \rho) w_{j}+Z_{0}(\xi, \eta, \rho)\left(f_{w}(\xi, \eta, \rho)-\right. \\
& \left.\sum_{j=i}^{m} N_{j}(\xi, \eta, \rho) f_{w j}\right)\left(\sum_{i=1}^{n t i p} N_{i}(\Gamma) K_{I}^{i}\right)+ \\
& Z_{0}(\xi, \eta, \rho)\left(g_{w}(\xi, \eta, \rho)-\right. \\
& \left.\sum_{j=i}^{m} N_{j}(\xi, \eta, \rho) g_{w j}\right)\left(\sum_{i=1}^{n t i p} N_{i}(\Gamma) K_{I I}^{i}\right)+ \\
& Z_{0}(\xi, \eta, \rho)\left(h_{w}(\xi, \eta, \rho)-\right. \\
& \left.\sum_{j=i}^{m} N_{j}(\xi, \eta, \rho) h_{w j}\right)\left(\sum_{i=1}^{n t i p} N_{i}(\Gamma) K_{I I I}^{i}\right)
\end{aligned}
$$

In the above equations, $N_{j}$ represents element shape functions for $\xi, \eta$, and $\rho$ local coordinates. $Z_{0}$ is the reset function that varies between 0 and 1. $f_{u}, g_{u}, h_{u}, f_{v}, g_{v}, h_{v}, f_{w}, g_{w}$ and $h_{w}$ represent mod-I, mod-II and mod-III displacement components transferred from the local coordinate system to the global coordinate system. $\mathrm{m}$ takes the value 10 or 20 depending on the element type. The expression of $\left(\sum_{i=1}^{n t i p} N_{i}(\Gamma) K_{I, I I, I I I}^{i}\right)$ represents 
the change of stress intensity factors of edge elements touching the crack front. $\Gamma$ is $\mathrm{s}$ the local isoparametric coordinate and takes values between -1 and $1[12,18]$.

\section{FINITE ELEMENT MODELLING and MATERIAL PROPERTIES}

In this section, information about finite element modeling, geometry, and material properties for nozzle-cylinder connections to be used in the analysis will be included.

As can be seen from Figure 3, an open-ended cylindrical pressure vessel placed on two saddles will be used in analysis carrying out. The finite element modeling of this vessel was made with the ANSYS package program. The inner diameter of the main cylinder is $500 \mathrm{~mm}$, the wall thickness is $25 \mathrm{~mm}$ and the cylinder length is $1000 \mathrm{~mm}$. The inner diameter of the nozzle is one sixth of the inner diameter of the cylinder. The nozzle thickness is also $25 \mathrm{~mm}$, but it varies only in the analyzes applied with the parameter of do/di. These rates will be shown in detail at the end of each analysis.

The choice of element types when completing finite element analysis is important as this is what helps create the mesh. In these analyzes, SOLID186, which is a 20-node 3D solid element with quadratic displacement behavior, was chosen. The element is defined by 20 nodes with three degrees of freedom per node: the node is offsets in the $\mathrm{x}, \mathrm{y}$, and $\mathrm{z}$ directions. The element supports plasticity, hyper elasticity, creep, stress hardening, large deflection and large tensile capabilities. Because of these features, it has been decided that it is a suitable element type and its ability to model complex geometries and represent the stress gradient effectively.

A crack is placed in the upper zone of the weld and the details of this crack modeling are given in Figure 1-2. While modeling the cracks, the coordinate axis in Figure 3 was taken as basis and the cracks were placed parallel to the $\mathrm{X}-\mathrm{Y}$ plane. Crack depth (a) and crack diameter (c) are the basic variables in this study and their values are specified in each analysis. Generally, the a/c ratio lies between 0,3 and 1,8 .
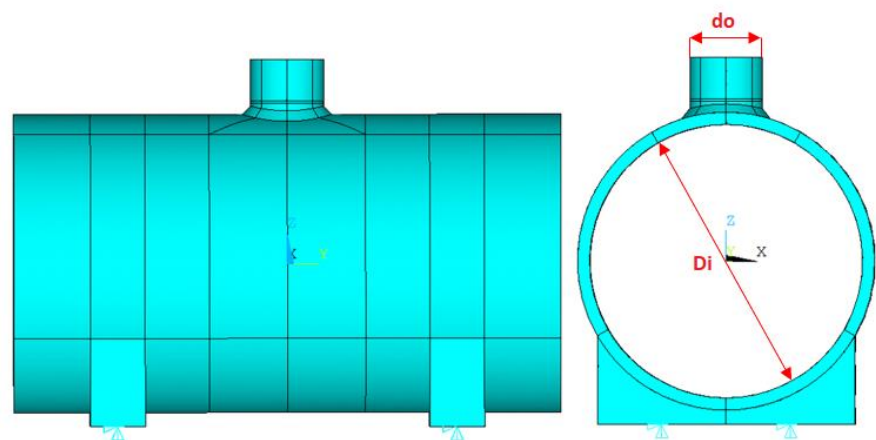

FIGURE 3: UNMESHED MODEL OF CYLINDRICAL PRESSURE VESSEL WITH A NOZZLE JUNCTION

For this study, three different materials were used in such structure. ASTM A266 Grade 2 carbon steel material with 190GPa Young's modulus, and 0,29 Poisson's ratio was used for the nozzle. For the shell material, SA-516 Grade 70 carbon steel pressure vessel plate, which is frequently used in both pressure vessels and industrial boilers, was chosen. The material properties of this material were 200GPa Young's modulus and 0,29 Poisson's ratio. Since the focal point of the study is the cracks of the outer wall of the nozzle,the saddles were far away to the critical region to be examined. Therefore, no specific material selection has been made for saddles. For saddles, Young's modulus was supposed as 290GPa and the Poisson's ratio was 0,3 . In addition, since the welding material was assumed to be rigid, it has nozzle material properties. Also, as can be seen in Figure 3, the structure was restricted to movement from the saddle sub-area. Apart from this, the vessel was free to move in all directions.

\section{VERIFICATION STUDY}

In this study, the aim is to obtain 3-dimensional mixedmode stress intensity factors of various crack profiles that may occur on the nozzle outer wall. The values of the stress intensity factors will be obtained using FCPAS as previously stated. A validation study will be done in this section to show that the method achieves the correct results. Newman-Raj's work was used to show the accuracy of the method. In summary, Newman and Raju [9] studied internal surface cracks in cylindrical pressure vessels in 1980. In their studies, stress intensity factors were determined by changing parameters such as crack length, crack depth, the wall thickness at certain rates. The study includes calculations in mode-I opening mode only. In this section, an elliptical crack was inserted into a cylindrical vessel, similar to Newman-Raju's approach. The model used by Newman-Raju and the resulting half finite element model is shown in detail in Figure 4 and 5, respectively.

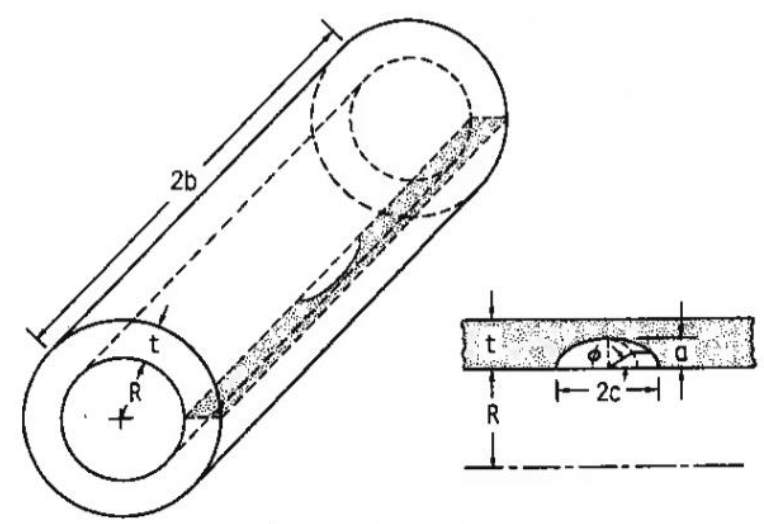

FIGURE 4: INTERNAL SURFACE CRACK IN A CYLINDER (NEWMAN-RAJU'S MODEL) 

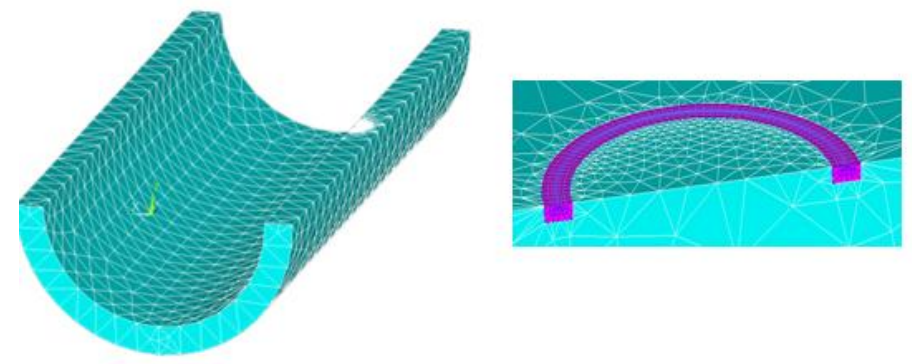

FIGURE 5: FINITE ELEMENT MODELING OF NEWMAN-RAJU MODEL

Newman-Raju studies only include KI SIFs calculations, and these calculations are given in the following equations.

$\mathrm{K}_{\mathrm{I}}=\frac{\mathrm{pR}}{\mathrm{t}} \sqrt{\pi \frac{\mathrm{a}}{\mathrm{Q}} \mathrm{F}}\left(\frac{\mathrm{a}}{\mathrm{c}}, \frac{\mathrm{a}}{\mathrm{t}}, \frac{\mathrm{R}}{\mathrm{t}}, \emptyset\right)$

$\mathrm{Q}=1+1,464(\mathrm{a} / \mathrm{c})^{1,65}$

$F_{i}=\frac{t}{R}\left(\frac{R_{0}^{2}}{R_{0}^{2}-R^{2}}\right)\left[\begin{array}{c}2 G_{0}-2\left(\frac{a}{R}\right) G_{1}+ \\ 3\left(\frac{a}{R}\right)^{2} G_{2}-4\left(\frac{a}{R}\right)^{3} G_{3}\end{array}\right]$

In this equation, $G_{j}$ values are taken from the tables in the current article in accordance with the parameters to be used. The inner diameter of the cylinder is determined as 250 $\mathrm{mm}$. Also, the wall thickness is $25 \mathrm{~mm}$, the crack radius and depth are $12,5 \mathrm{~mm}$ and the internal pressure to be applied is $10 \mathrm{MPa}$. In line with this information, KI stress intensity factor values are calculated at 9 different points from 0 degrees to 180 degrees with Newman-Raju approach. As a result of the calculations obtained, the comparison results are given in Figure 6 below.

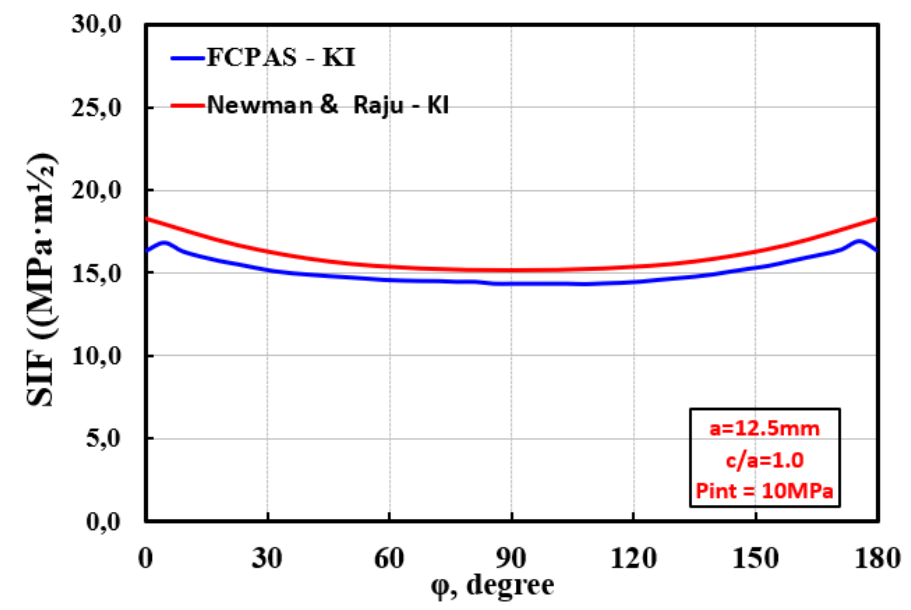

FIGURE 6: VERIFICATION OF FCPAS SOLUTION WITH NEWMAN \& RAJU APPROACH
As can be seen from Figure 6, the results obtained are very close to each other and differences of SIFs are nearly six per cent at the point where the difference is highest. There are some factors in making this difference. In the current study, there is a lack of information regarding boundary conditions and determination of cylinder length. For this reason, a cylindrical pressure vessel seated on 2 saddles was used in verification in order to be consistent with other analysis. In this way, all boundary conditions are applied under saddles and the cylinder is completely free to movement in all directions. In addition, KII and KIII values were ignored in the study. This difference is quite reasonable when these factors are taken into consideration.

\section{PARAMETRIC STUDIES}

In this section, the mixed-mode stress intensity factors extending along the crack line in modeled crack profiles with finite elements method under various parameters will be computed. In all analyzes the cylinder dimensions will be fixed as $D_{i}=500 \mathrm{~mm}$ and $T=25 \mathrm{~mm}$. Changes will be based on nozzle and crack sizes. The parameter analysis to be made will take place in 4 stages. First, the mixed mode SIFs will be examined by obtaining elliptical crack profiles of different sizes by changing the ratio $(\mathrm{a} / \mathrm{c})$ of crack depth to crack radius under a constant internal pressure. Subsequently, the internal pressure changes will be examined, provided that they remain in the linear elastic zone in the vessel. Then, by changing the nozzle thickness, the effect of $r_{\mathrm{o}} / \mathrm{r}_{\mathrm{i}}$ change on SIFs will be figured out. Finally, the various local forces on the nozzle will be combined in 8 different ways and examined.

\subsection{Changing Crack Depth Magnitude (a/c ratio)}

In this section, half elliptical surface crack profiles were modelled by keeping the crack radius (c) constant and only modifying the crack depth (a). A representative semi-elliptical profile showing the locations of the crack depth and crack diameter is shown in Figure 7.

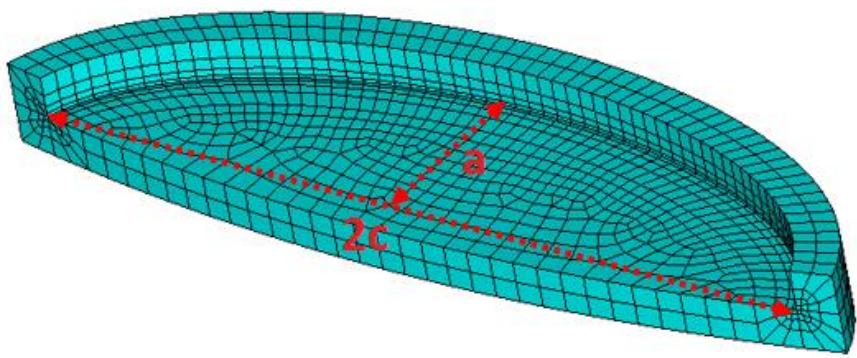

FIGURE 7: A REPRESENTATIVE VIEW OF SEMI-ELLIPTICAL CRACK PROFILE

In each analysis c value is $12,5 \mathrm{~mm}$ and constant. In addition, the crack depth was changed in each analysis and mixed mode SIF values were obtained for 7 different crack profiles from $\mathrm{a} / \mathrm{c}=0,3$ to $\mathrm{a} / \mathrm{c}=1,8$. The results obtained were grouped separately for mode-I (opening), mode-II (sliding) and mode-III (tearing). KI Stress Intensity Factors results obtained for mode-I status are shown in Figure 8, KII Stress Intensity 
Factors results obtained for mode-II status are shown in Figure 9 and KIII Stress Intensity Factors results obtained for mode-III status are shown in Figure 10.

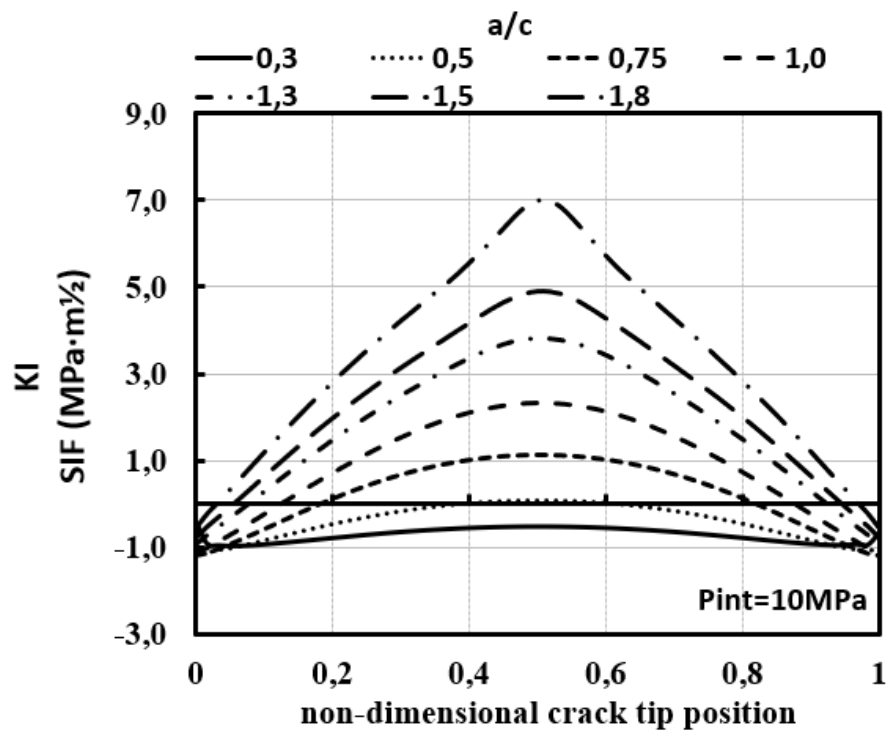

FIGURE 8: MODE-I SIF DISTRIBUTIONS ACCORDING TO THE CHANGE IN CRACK DEPTH (a) ALONG THE CRACK FRONTS $\mathrm{c}=6,25-\mathrm{Pint}=10 \mathrm{MPa}$

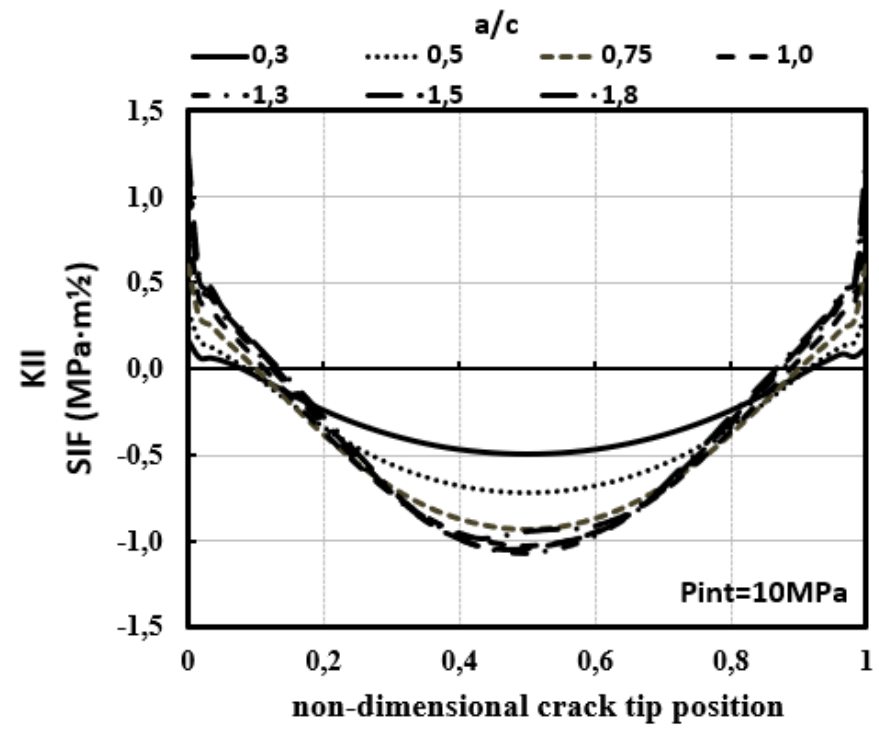

FIGURE 9: MODE-II SIF DISTRIBUTIONS ACCORDING TO THE CHANGE IN CRACK DEPTH (a) ALONG THE CRACK FRONTS $\mathrm{c}=6,25-\mathrm{Pint}=10 \mathrm{MPa}$

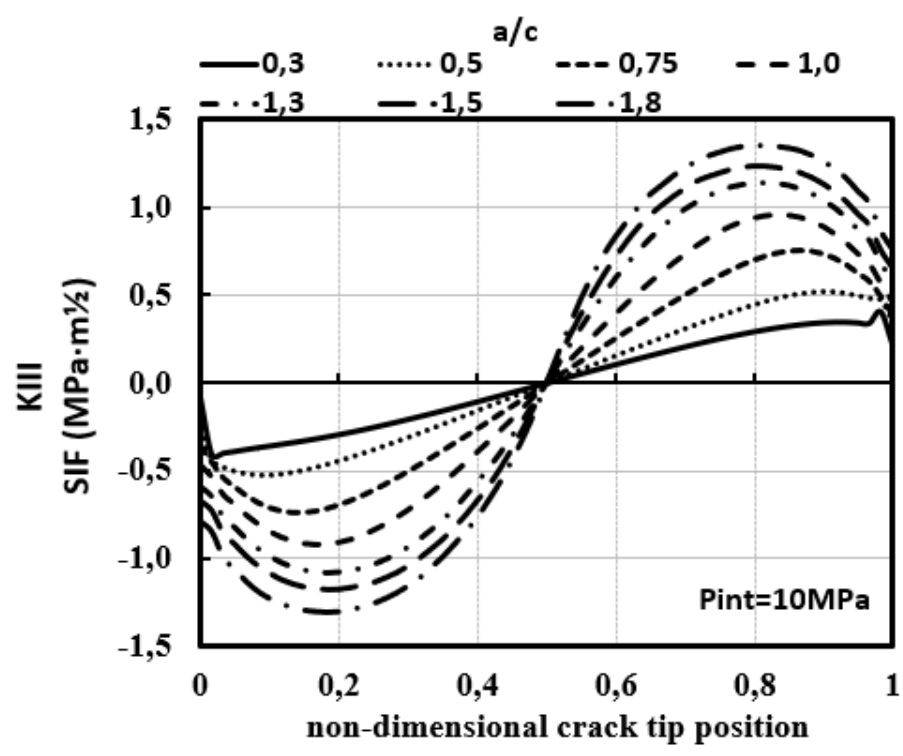

FIGURE 10: MODE-III SIF DISTRIBUTIONS ACCORDING TO THE CHANGE IN CRACK DEPTH (a) ALONG THE CRACK FRONTS $\mathrm{c}=6,25-\mathrm{Pint}=10 \mathrm{MPa}$

As it can be seen from the graphics, with the increase of the crack depth, the material approaches the fracture state more and especially the mode-I opening effect appears clearly. The same situation is observed in the case of mode-II and Mode-III, but it changes linearly from negative to a positive value along the crack line, especially in the case of mode-III. This is because under mode-III loading, crack surfaces tend to deform opposite each other around the crack tip center point. Moreover, the sudden increase or decrease in the stress intensity factors at both crack tips is caused by the free-surface effect, and it is more obvious in the KII graph. This situation is ignored in the calculations.

\subsection{Changing Internal Pressure (Pint)}

In this section, a study has been done on how internal pressure variation affects SIF values. Considering the equations introduced by Newman-Raju, the internal pressure increase is expected to increase the SIF values linearly as the internal pressure directly affects the hoop stress in the cylinder (ref: Eq.4).

However, these equations were given for perfect cylinder internal surface cracks without nozzle connection and mode-I cases only. In this study, it was found important to examine these analyzes because the cracks are located on the outer surface of the nozzle and the mixed-mode conditions are examined. In the analysis, the crack depth is half the radius of the $\operatorname{crack}(\mathrm{a} / \mathrm{c}=0,5)$. In addition, analyzes were carried out for 5 different internal pressure magnitudes and the SIF results are given in Figures 1113.

The internal pressure to be applied during the analysis should not reach the limit load. Considering the Perfect Plasticity and Tresca criteria, the force and limit required for the initial yield to be realized can be calculated by the following equations (Eq.7 Eq.8) [19]. 
First yield: $\quad p_{y}=\frac{\sigma_{y}}{2}\left(1-\left(\frac{r_{i}}{r_{0}}\right)^{2}\right)$.

$$
\text { Limit load: } \quad p_{l}=\sigma_{y} \ln \left(\frac{r_{i}}{r_{0}}\right) \text {. }
$$

Since the yield strength of the shell is smaller than the nozzle (260MPa for shell, 290MPa for nozzle), the calculations were made to obtain the limit load in the shell. As a result of these calculations, pressure values less than $24,7 \mathrm{MPa}$ should be applied to the container in order not to reach the yield point. For this reason, analyzes with a maximum limiting value of $15 \mathrm{MPa}$ were undertaken.

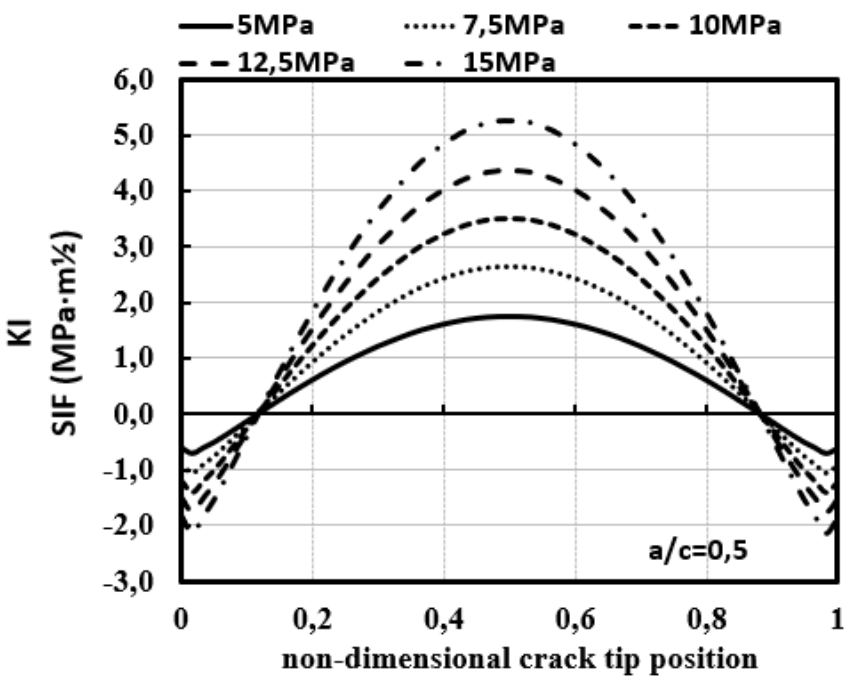

FIGURE 11: MODE-I SIF DISTRIBUTIONS ACCORDING TO THE CHANGE IN INTERNAL PRESSURE (Pint) ALONG THE CRACK FRONTS, a/c=0,5

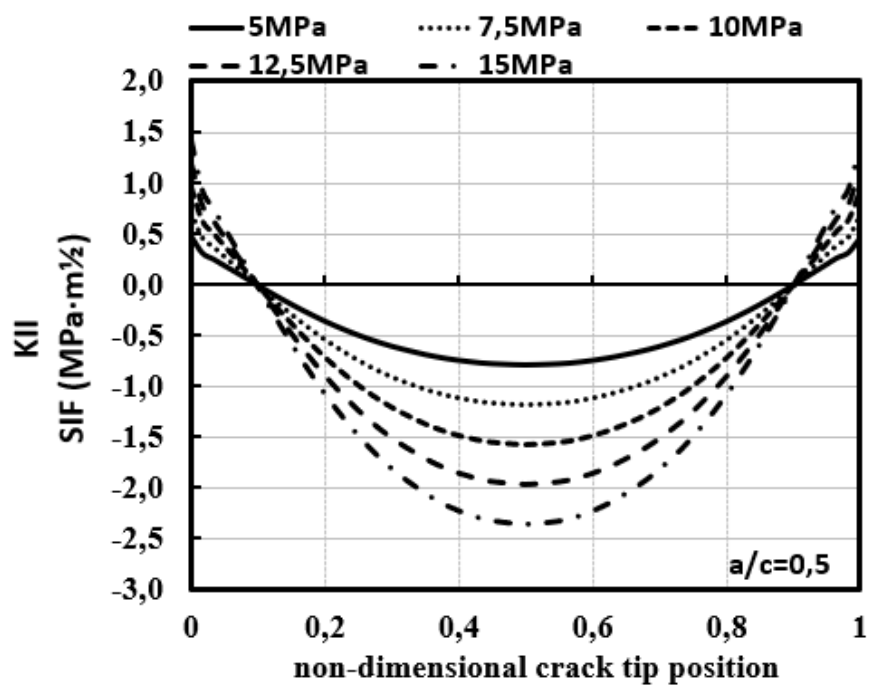

FIGURE 12: MODE-II SIF DISTRIBUTIONS ACCORDING TO THE CHANGE IN INTERNAL PRESSURE (Pint) ALONG THE CRACK FRONTS, a/c $=0,5$

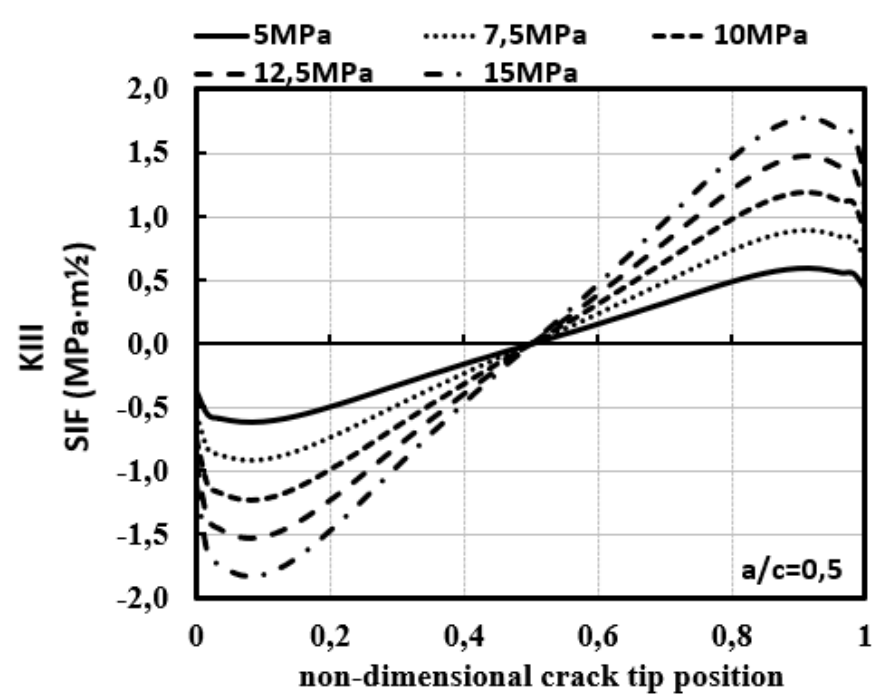

FIGURE 13: MODE-III SIF DISTRIBUTIONS ACCORDING TO THE CHANGE IN INTERNAL PRESSURE (Pint) ALONG THE CRACK FRONTS a/c $=0,5$

When the computed SIF values given in the graph are examined, a linear increase is seen in each crack point except the turning points. This situation is compatible with Equation 4. In all cases the opening effect (mode I) is much more dominant than mode-II and mode-III effects. Since the crack depth is half the crack radius, there is much more stress build-up at the crack midpoint compared to the crack tip. This accumulation becomes more pronounced in Mode-I and mode-II as the internal pressure increases.

In summary, in this problem, the only force acting on the system is the internal pressure and the stress shows a symmetrical distribution towards the outer walls. In Mode I, a tensile stress normal to the crack plane occurs. For this reason, a full opening state occurs in the crack center. In the mode II state, the crack is in the in-plane shear state. That is, it is under a shear stress that acts parallel to the crack plane and perpendicular to the crack front. For this reason, the sliding effect in the crack center is more pronounced than the crack tip. On the other hand, in the case of Mode III, the crack is in the out-of-plane shear state. In other words, there is a shear stress parallel to the crack plane and acting parallel to the crack front. For this reason, the tearing effect is zeroed in the center and is more pronounced at the crack tip.

\subsection{Changing Nozzle Diameter (do/di)}

In this section, the outer diameter / inner diameter ratio (do/di) will be changed by keeping the nozzle inner diameter constant. In other words, SIF changes will be analyzed using the change in nozzle thickness. In these analyzes, the outer nozzle diameter is constant and $133,3 \mathrm{~mm}$. The a/c ratio is 0,5 . The analyzes were carried out in 5 steps for different do/di ratios and the results obtained are given in Figures 14-16. 


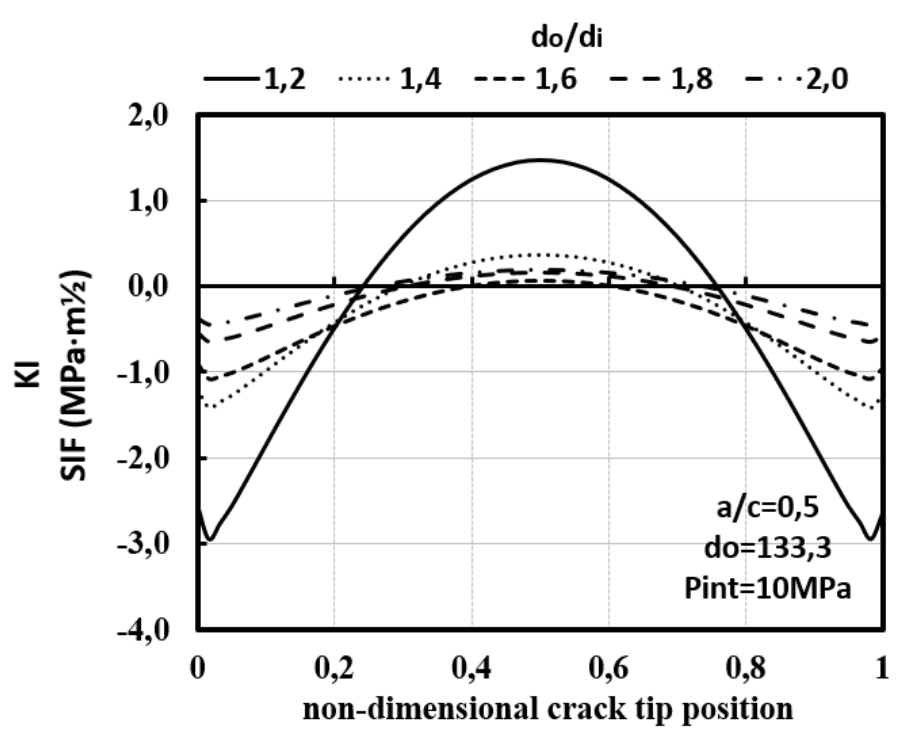

FIGURE 14: MODE-I SIF DISTRIBUTIONS ACCORDING TO THE CHANGE IN do/di RATIOS ALONG THE CRACK FRONTS, a/c=0,5 - do $=133,3 \mathrm{~mm}$

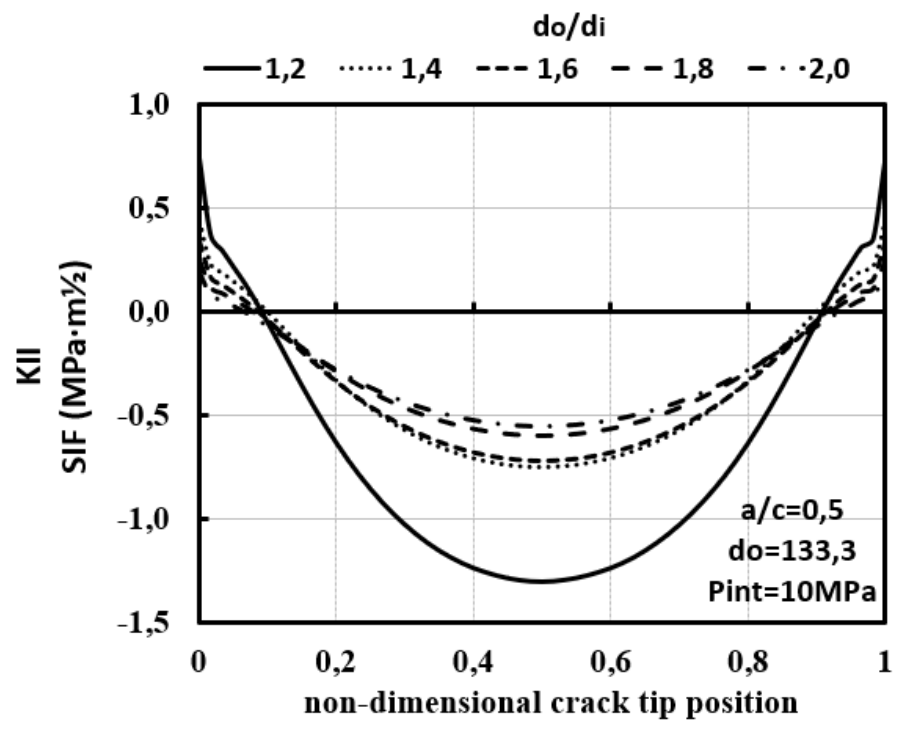

FIGURE 15: MODE-II SIF DISTRIBUTIONS ACCORDING TO THE CHANGE IN do/di RATIOS ALONG THE CRACK FRONTS, $\mathrm{a} / \mathrm{c}=0,5-\mathrm{do}=133,3 \mathrm{~mm}$

The least nozzle thickness is the case where do/di $=1,2$. At this rate, the crack depth has reached approximately $70 \%$ of the nozzle thickness. When $\mathrm{do} / \mathrm{di}=1,2$, hoop stress is approximately $48 \%$ higher than $\mathrm{do} / \mathrm{di}=1,4$. The difference between hoop stress at 1,6 and 1,4 do/di ratios is about $27 \%$. On the other hand, SIF values increased by an average of $35 \%$ at this point as can be seen from the figures. Considering all these situations, this increase is quite reasonable. In general, as expected, SIF values decrease with increasing nozzle thickness.

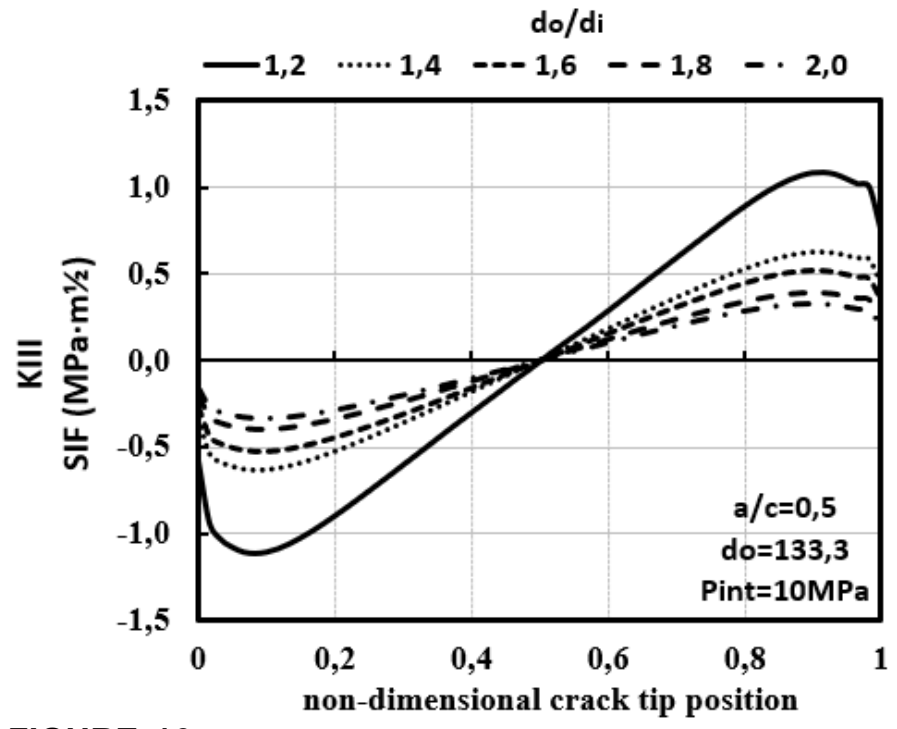

FIGURE 16: MODE-III SIF DISTRIBUTIONS ACCORDING TO THE CHANGE IN do/di RATIOS ALONG THE CRACK FRONTS, $\mathrm{a} / \mathrm{c}=0,5-\mathrm{do}=133,3 \mathrm{~mm}$

\subsection{External Loading Applications}

In this section, local loads on the system from the nozzle center were examined in different combinations. First, the SIF values are calculated by analyzing the tensile force (Vz), longitudinal force $(\mathrm{Vy})$, and circumferential force $(\mathrm{Vx})$ independently. Load conventions can be seen in Figure 17.

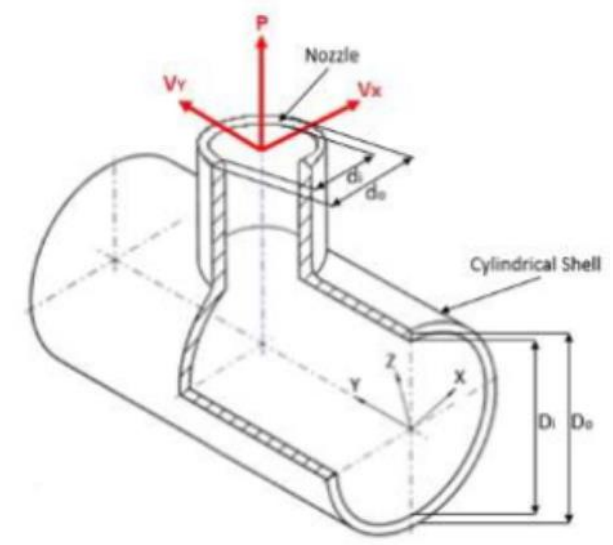

FIGURE 17. LOAD CONVENTIONS FOR THE MODEL

Then, calculations are made for all variations in groups of 2, 3 and 4. Single axes loadings are represented by black color, 2 axes loading variations with green color, 3 axes loading combination with red and finally 3 axes loading with pressure loading combination with purple. The results obtained are shown in Figures 18-20. 


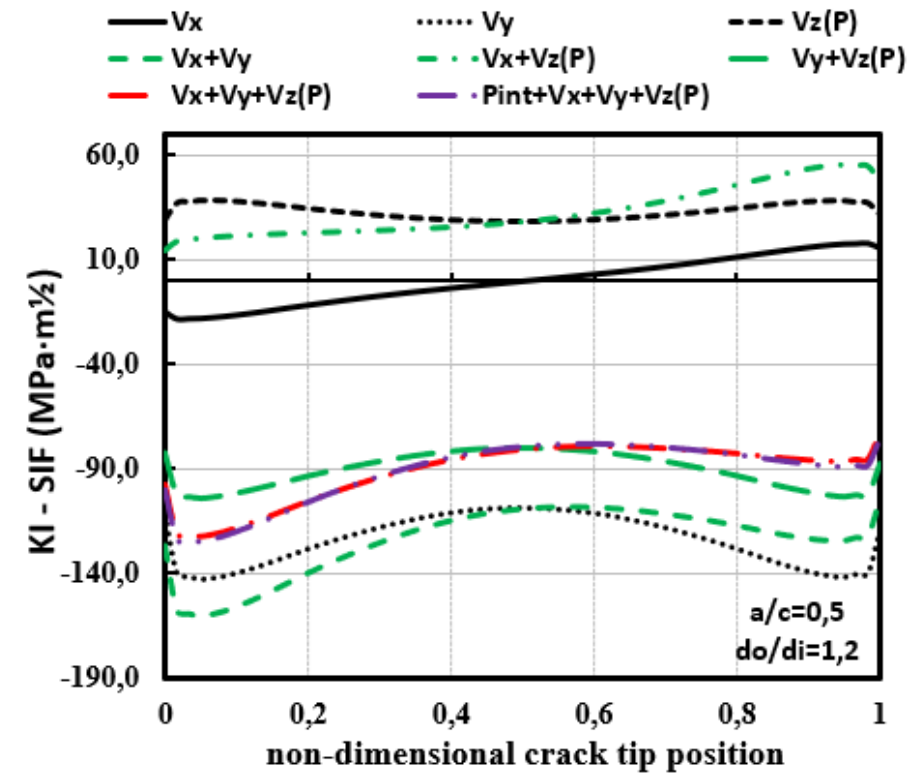

FIGURE 18: MODE-I SIF DISTRIBUTIONS ACCORDING TO THE CHANGE IN COMBINE EXTERNAL LOADINGS ALONG THE CRACK FRONTS, a/c=0,5 - do/di=1,2

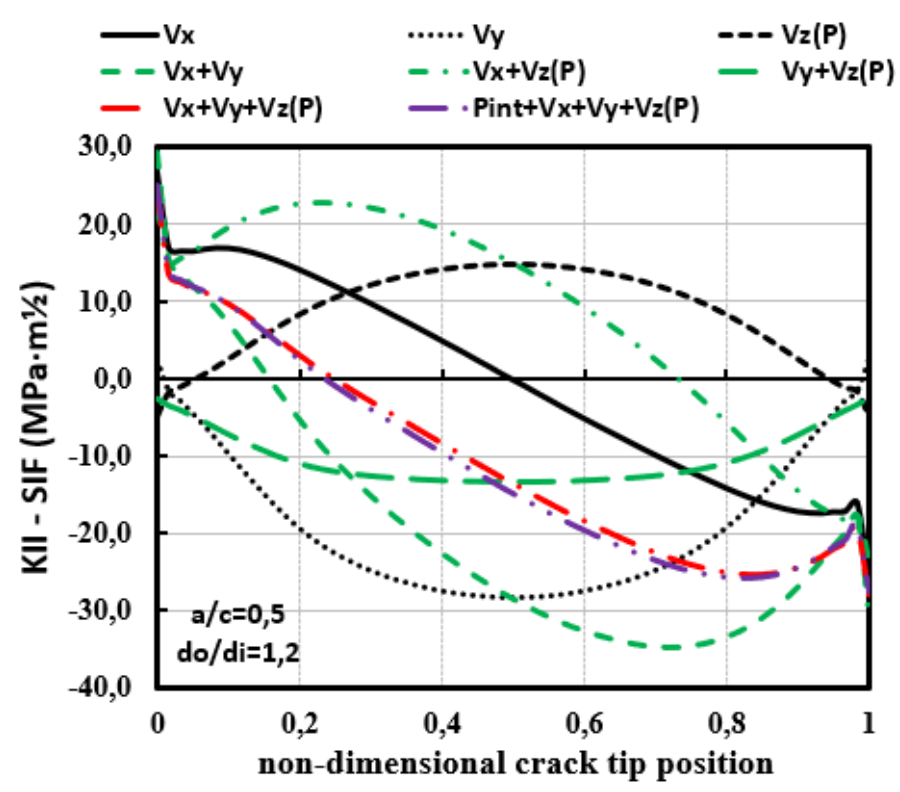

FIGURE 19: MODE-II SIF DISTRIBUTIONS ACCORDING TO THE CHANGE IN COMBINE EXTERNAL LOADINGS ALONG THE CRACK FRONTS, $\mathrm{a} / \mathrm{c}=0,5-\mathrm{do} / \mathrm{di}=1,2$

In these analyzes, $\mathrm{Vx}, \mathrm{Vy}$ and $\mathrm{Vz}$ are $1000 \mathrm{kN}$ for each case. Internal pressure is included in combined loading only in the last case and its value is $10 \mathrm{MPa}$. As can be seen from the Mode I graph, the situation where the SIF values are the highest in the external loading situations are the cases with tensile loading (Vz). SIF values are the highest even when single Vz loading, because the tensile force directly triggers the opening of the crack. In Mode-III case, Vz and Vy forces play the leading roles in tearing effect. Since the direction of the force changes in multiple loads, an SIF rise is not observed as dominant as singular loads in the opening, sliding, and tearing modes. The most interesting observation that can be said for the 3 graphs here alone is that the internal pressure has almost no effect on SIF changes.

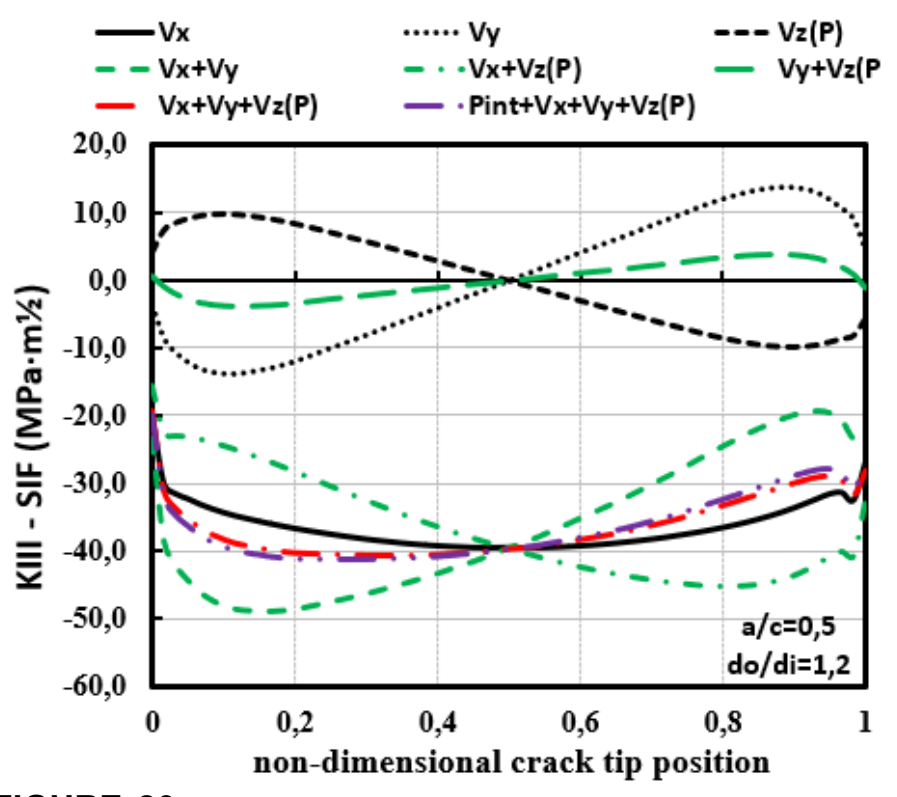

FIGURE 20: MODE-III SIF DISTRIBUTIONS ACCORDING TO THE CHANGE IN COMBINE EXTERNAL LOADINGS ALONG THE CRACK FRONTS, a/c=0,5 - do/di=1,2

\section{CONCLUSIONS}

In pressure vessels, the nozzle region and welded areas are the parts where the highest and most complex stress density is experienced due to the existing opening. While the system is only under internal pressure, the highest stress regions occur at the nozzle-cylinder intersections, by the way these critical regions may change depending on the direction and magnitude of the force especially in external local loads. Identifying these critical locations and potential failure mechanisms is very important to prevent damage to such structures. There are some SIF calculation methods for cracks located on perfect cylinders in the literature, but these methods only provide calculations for the opening mode-I caused by the hoop stress. On the other hand, although studies based on fracture mechanics related to nozzlecylinder intersections have been made, there is no definitive solution for calculating mixed mode stress intensity factors in potential cracks that may occur. For this purpose, in this study, alternative solutions related to the calculation of stress intensity factors under internal pressure and various external local loads of elliptical cracks located at a location very close to the nozzlecylinder intersection (upper side of the welding) are produced. As a result of the studies, it was observed that the SIF values increased in direct proportion to the magnitude of the loading and the size of the crack only in cracks under internal pressure. On the other hand, it was determined that the direction of the 
force is more effective than the magnitude of the force in external loads applications. For example, the single tensile force $(\mathrm{Vz})$ of $1000 \mathrm{kN}$ applied from the nozzle center has a greater KI SIF value than the local forces applied in 3 different directions simultaneously $(1000 \mathrm{kN} \mathrm{Vx}+1000 \mathrm{kN} \mathrm{Vy}+1000 \mathrm{kN} \mathrm{Vz})$ and the crack tends to open more.

In summary, this study discusses in detail the SIF calculations for surface cracks that may occur in the nozzle outer wall in nozzle-cylinder connection problems and provides a wide parameter study. Mixed-mode SIF calculations for cracks that may occur in the crotch corner in nozzle-cylinder connection problems are planned to be anlysed and presented in future studies.

\section{ACKNOWLEDGEMENTS}

The work of M. Bozkurt was supported by the Republic of Turkey Ministry of National Education under Grant MoNE1416/YLSY.

\section{REFERENCES}

[1] Liu, R., Huang, M., Peng, Y., Wen, H., Huang, J., Ruan, C., $\& \mathrm{Li}$, Q. (2018). Analysis for crack growth regularities in the nozzle-cylinder intersection area of Reactor Pressure Vessel. Annals of Nuclear Energy, 112, 779-793.

[2] Murtaza, U. T., \& Hyder, M. J. (2015). The effects of thermal stresses on the elliptical surface cracks in PWR reactor pressure vessel. Theoretical and Applied Fracture Mechanics, 75, 124136.

[3] Jin, T., Wang, Z., Wang, Q., Wang, D., Li, Y., \& Zhou, M. (2019). Weibull stress analysis for the corner crack in reactor pressure vessel nozzle. Advances in Mechanical Engineering, 11(12), 1687814019893567.

[4] Susmikanti, M., Himawan, R., Hartini, E., \& Rokhmadi, R. (2019). Analysis of 3d semi-elliptical crack on reactor pressure vessel wall with load stress and crack ratio. Jurnal Teknologi Reaktor Nuklir Tri Dasa Mega, 21(1), 33-38.

[5] Akrami, V., \& Erfani, S. (2017). An analytical and numerical study on the buckling of cracked cylindrical shells. Thin-Walled Structures, 119, 457-469.

[6] Estekanchi, H. E., \& Vafai, A. (1999). On the buckling of cylindrical shells with through cracks under axial load. Thinwalled structures, 35(4), 255-274.

[7] Alizadeh, E., \& Dehestani, M. (2018). Analytical and numerical fracture analysis of pressure vessel containing wall crack and reinforcement with CFRP laminates. Thin-Walled Structures, 127, 210-220.

[8] Subbaiah, A., \& Bollineni, R. (2020). Stress Intensity Factor of Inclined Internal Edge Crack in Cylindrical Pressure Vessel. Journal of Failure Analysis and Prevention, 20(5), 1524-1533.
[9] Newman Jr, J. C., \& Raju, I. S. (1980). Stress-intensity factors for internal surface cracks in cylindrical pressure vessels.

[10] Kirkhope, K. J., Bell, R., \& Kirkhope, J. (1991). Stress intensity factors for single and multiple semi-elliptical surface cracks in pressurized thick-walled cylinders. International Journal of Pressure Vessels and Piping, 47(2), 247-257.

[11] Hachi, B. E. K., Rechak, S., Belkacemi, Y., \& Maurice, G. (2005). Modelling of elliptical cracks in an infinite body and in a pressurized cylinder by a hybrid weight function approach. International Journal of Pressure Vessels and Piping, 82(12), 917-924.

[12] Ayhan, A. O., \& Nied, H. F. (2002). Stress intensity factors for three-dimensional surface cracks using enriched finite elements. International Journal for Numerical Methods in Engineering, 54(6), 899-921.

[13] Ayhan, A. O. (2011). Simulation of three-dimensional fatigue crack propagation using enriched finite elements. Computers \& Structures, 89(9-10), 801-812.

[14] Bozkurt, M., Ayhan, A. O., Yaren, M. F., \& Siriç, S. (2016). Finite element modeling and experimental studies on mixed mode-I/III fracture specimens. Frattura ed Integrità Strutturale, 10(35), 350-359.

[15] Kurt, E., \& Ayhan, A. O. (2019). Three-dimensional mixedmode stress intensity factors for deflected internal surface cracks in thin and midsize-thick-walled spherical pressure vessels. International Journal of Pressure Vessels and Piping, 171, 10-33.

[16] Bozkurt, M., Nash, D., \& Uzzaman, A. (2019, July). Investigation of the stresses and interaction effects of nozzlecylinder intersections when subject to multiple external loads. In Pressure Vessels and Piping Conference (Vol. 58943, p. V003T03A028). American Society of Mechanical Engineers.

[17] Bozkurt, M., Nash, D., \& Uzzaman, A. (2020, October). Effect of the internal pressure and external loads on nozzles in cylindrical vessel. In IOP Conference Series: Materials Science and Engineering (Vol. 938, No. 1, p. 012007). IOP Publishing.

[18] Ayhan, A. O. (2000). Finite element analysis of nonlinear deformation mechanisms in semiconductor packages, Ph.D. Dissertation Lehigh University, 1999.

[19] J. Spence, A. S. Tooth, Pressure Vessel Design Concepts and Principles, CRC Press, 2012 